\title{
Static Stiffness Parametric Studies of Newly Conceptualized Inter Shaft Squeeze Film Damper (ISSFD) Rings
}

\author{
H. M. Shivaprasad', G. Giridhara', V. Arunkumar ${ }^{2}$

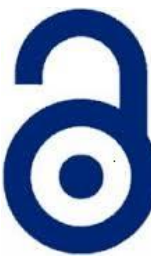 \\ Received: 25 March 2019 \\ Accepted: 09 May 2019 \\ Published: 20 June 2019 \\ Publisher: Deer Hill Publications \\ (c) 2019 The Author(s) \\ Creative Commons: CC BY 4.0
}

\begin{abstract}
Most of the modern gas turbine engine designs requiring super critical operations will often have squeeze film dampers (SFDs) on the high pressure spool bearing as an inevitable feature. However, Squeeze Film Dampers are not very common for inter-shaft bearing applications and are still in the research and development stage. The current effort concentrates on static stiffness parametric studies based on newly conceptualized intershaft squeeze film damper (ISSFD) ring design suitable for space constrained intershaft bearing application of a typical two spool configured system. The work involves static stiffness evaluation of three and four grooves ISSFD rings by varying the groove angle/groove length/subtended angle of groove $\&$ hence the overlapping angle of grooves by conducting static tests on a dedicated static stiffness evaluation test rig designed and fabricated for the purpose. The pattern of circumferential variation of stiffness of each ring is studied and the results revealed a typical trend of decreasing stiffness in ISSFD ring with the increase in groove angle and hence the overlapping angle of grooves. The static stiffness parametric studies has resulted in developing an ideal profile of ISSFD ring having six grooves that exhibited axisymmetric pattern of circumferential variation of stiffness. When used in a space constrained intershaft bearing plane of a typical two spool gas turbine engine, the ideal ISSFD ring profile would exhibit the best damping performance.
\end{abstract}

Keywords. Inter Shaft Squeeze Film Damper (ISSFD), Gas Turbine Engine, Static stiffness, two spools, grooves.

\section{INTRODUCTION}

A squeeze film damper (SFD) is essentially a simple device consisting of an oil film interposed between the nonrotating outer race (sleeve) of a rolling element bearing and its housing. SFDs are lubricated elements providing viscous damping in mechanical systems. They help in dissipation of vibration energy, isolation of structural components and improve the dynamic stability characteristics of inherently unstable rotor-bearing systems. For the high speed turbo machine rotors to work closer to critical speeds, damping is essential. Off late, SFDs have become very essential components of high speed Turbo machinery because of their simplicity in design and high potential to deliver desired level of damping. While applications of SFD has become very common, the necessity of the same in an inter-shaft bearing plane has still not been realized from practical application point of view. It is observed that, in real practical sense, there is lot of potential for the development of newer versions of SFD design suitable for a space constrained intershaft bearing plane of two spool configured system. Also, most of the work that is reported in the past doesn't look to be feasible from practical application point of view of a typical space constrained gas turbine engine setup and the unavailability of SFD design for an intershaft bearing plane still continues.

The concept of squeeze film damping is explained by Luis San Andres [1] and he has shown the necessity of squeeze film dampers along with the applications. He has explained various models of squeeze film dampers with design criteria and the recent developments in the domain of squeeze film dampers. Gupta, et al. [2] tested an improved intershaft squeeze film damper (ISSFD) by considering two design modifications for analysis and tested them experimentally. Zeidan, et al. [3\&4] highlighted the advantages of Squeeze film dampers and reported that over damped condition of the supports would reduce the effective damping in high speed rotating machinery. ElShafei, et al. [5, 6, $7 \& 8$ ] showed that the intershaft squeeze film damper is unstable above the engine's first critical speed. They have reported that the intershaft dampers are stable super critically only in a configuration in which the oil film does not rotate. E. J. Gunter, et al. [9] reported that the effective stiffness and damping coefficients can be

H.M.Shivaprasad', G.Giridhara', V.Arunkumar²

'B.M.S.College of Engineering, Bull Temple Road, Bangalore-560 019

${ }^{2}$ Dr.Ambedkar Institute of Technology, Outer ring road, Bangalore-560 056

E-mail: shivaprasad.mech@bmsce.ac.in

Reference: H. M. Shivaprasad, G. Giridhara, V. Arunkumar (2019). Static Stiffness Parametric Studies of Newly Conceptualized Inter Shaft Squeeze Film Damper (ISSFD) Rings. International Journal of Engineering Materials and Manufacture, 4(2), 77-84. 
determined using the values of rotor amplitude, phase angle and unbalance forces for a rigid rotor. M. Jayaraman and V. Arunkumar [10] have introduced the concept of flexible supports or flexible mounts which are mounted in between the bearing and the shaft in order to reduce excessive vibration levels in the machinery. H. M. Shivaprasad and $G$. Giridhara [11] conducted preliminary studies on newly conceptualized inter-shaft squeeze film damper (ISSFD) rings having desired number of discontinuous grooves in the annular space. To overcome the limitations and problems associated with the existing SFD models for Intershaft bearing application, they have proposed new versions of ISSFD rings having circumferential grooves of very thin width which actually represents the squeeze oil film thickness. In a real practical sense, they have proposed a compatible component facilitating the radial squeezing mechanism, where squeeze film oil could be introduced, thus resulting in squeeze film damping. Their simulation result and experimental result with regard to static stiffness value correlate well. Hibner, et al. [12\&13], Alderson, et al. [14], Qihan Li, et al. [15\&16], J.B. Courage [17], Shende, et al. [18] and many more researchers have reported their work related to intershaft squeeze film dampers.

In this research work, Static stiffness parametric studies based on newly conceptualized ISSFD ring design [11] is carried out by varying the geometric parameters viz., number of grooves, groove angle/groove length/subtending angle of groove and hence the overlapping angle of grooves. As such an attempt has been made here to develop practically feasible, ideal profile of ISSFD ring, suitable for intershaft bearing of a typical space constrained, two spool gas turbine engine. Figure 1 shows the schematic of a typical two spool configured gas turbine engine. When mounted on intershaft bearing (bearing-4), an ideal ISSFD ring profile would exhibit the best damping performance and effectively attenuate vibrations amplitude in the intershaft bearing plane.

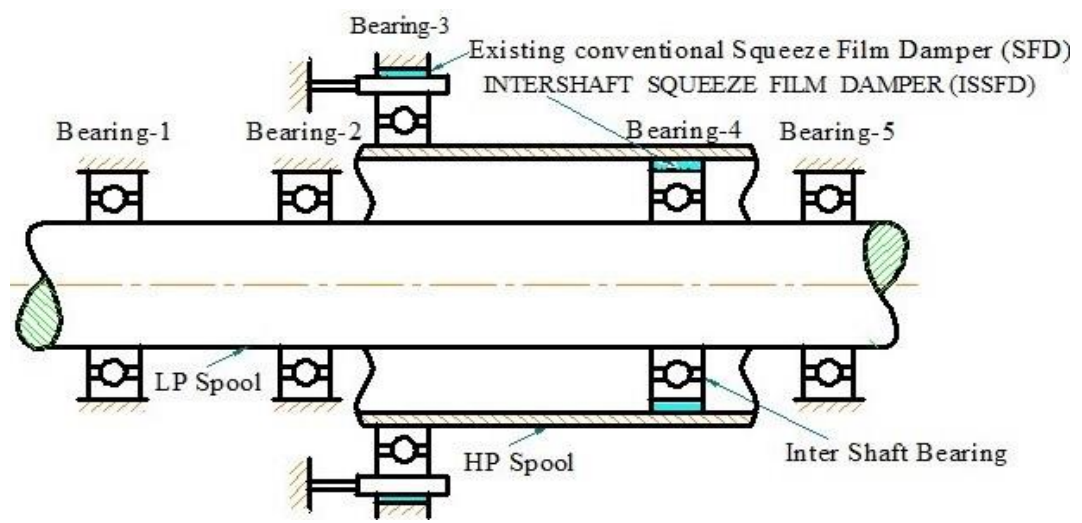

Figure 1: Schematic of a typical two spool configured gas turbine engine

\section{BACKGROUND}

An ISSFD ring is essentially designed to deform when a radial load is applied. When the circumferential variation of stiffness of ISSFD ring follows axisymmetric pattern, circumferential deformation of the ring will be axisymmetric. Under axisymmetric pattern of circumferential deformation of the ring, squeezing of oil film will have axisymmetric pattern and hence the damping effect created by such an ISSFD ring will be very effective. Under working conditions, an ISSFD ring with axisymmetric pattern of circumferential variation of stiffness would provide effective damping as the absorption of kinetic energy of the moving surfaces would happen in an axisymmetric pattern. Therefore it is necessary to develop an ISSFD ring profile that exhibits axisymmetric pattern of circumferential variation of stiffness. With this background, static stiffness parametric studies is carried out with an intention to develop an ideal ISSFD ring profile that exhibits axisymmetric pattern of circumferential variation of stiffness.

\section{MANUFACTURE OF ISSFD RINGS}

For parametric studies, two sets containing four ISSFD rings in each set, one with three number of grooves and another with four number of grooves are fabricated by varying the geometric parameters and taken up for studies. The dimensions on ISSFD ring that would fit a typical two spool small gas turbine engine are chosen as; $68 \mathrm{~mm}$ outer diameter, $62 \mathrm{~mm}$ inner diameter and $20 \mathrm{~mm}$ width along the shaft axis. Considering the radial thickness of the ring and after deliberations, the width/thickness of oil grooves is appropriately chosen as $0.3 \mathrm{~mm}$.

Figure $2 \mathrm{a}$ shows the profile drawing of three grooves ISSFD ring with $135^{\circ}$ groove angle. The groove angles considered for three grooves ISSFD rings are $135^{\circ}, 150^{\circ}, 165^{\circ}$ and $180^{\circ}$ that gives overlap angles of $15^{\circ}, 30^{\circ}, 45^{\circ}$ and $60^{\circ}$ respectively. The groove angle/groove length/subtended angle of groove and hence the overlapping angle of grooves is appropriately increased in steps of $15^{\circ}$, essentially to study the circumferential variation of stiffness. Figure $2 \mathrm{~b}$ shows the profile drawing of four grooves ISSFD ring with $105^{\circ}$ groove angle. The groove angles considered for four grooves ISSFD rings are $105^{\circ}, 120^{\circ}, 135^{\circ}$ and $150^{\circ}$ that gives overlap angles of $15^{\circ}, 30^{\circ}, 45^{\circ}$ and $60^{\circ}$ respectively. Here also the groove angle /groove length/subtended angle of groove and hence the overlap angle of grooves is 
increased in steps of $15^{\circ}$. Spring steel is selected as the material for ISSFD rings considering its high Yield strength and capability to regain its original shape despite significant deflection. The rings are fabricated by carrying out $\mathrm{CNC}$ turning operation and wire EDM processes. Stress relieving is done to relieve the internal residual stresses developed during the machining process. Figure 3 shows the Photographs of sequence of operations performed during the fabrication of ISSFD rings.

\section{STATIC TEST RIC}

The static test rig facilitates loading of the ISSFD ring and measurement of deflection along the load line. The main components of static test rig are; base plate, frame, two V-blocks, a mandrel for mounting of ISSFD ring, loading unit, load cell and a digital dial indicator. Figure 4 shows different views of static test rig where in a mandrel along with the ISSFD ring is supported between two V-blocks which are mounted on the base plate. The loading unit includes the screw rod arrangement which is manually operated to apply load. The load cell connected to the loading unit measures the load applied on the ring. A digital dial indicator connected to the loading unit measures the deflection of the ISSFD ring.

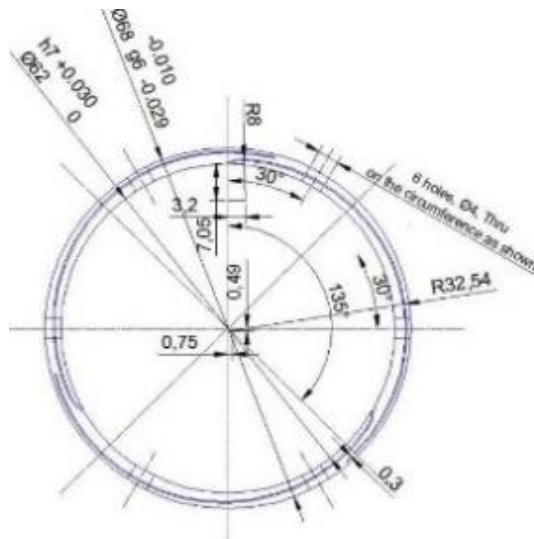

(a) 3 grooves $-135^{\circ}$

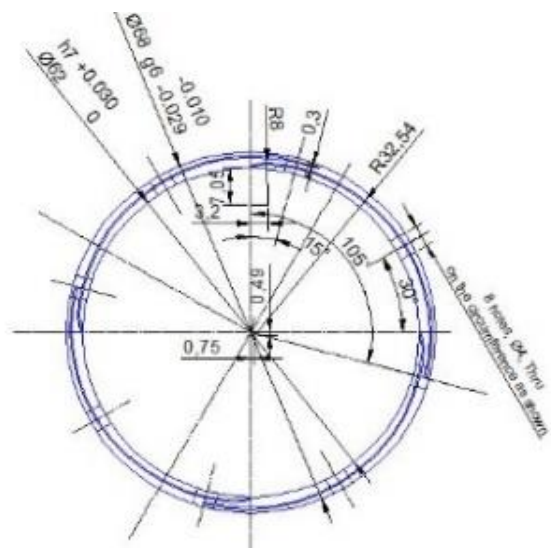

(b) 4 grooves- $105^{\circ}$

Figure 2: Drawings of 3\&4 grooves ISSFD rings showing variation of groove angle

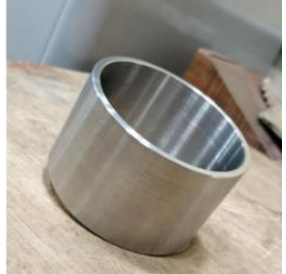

(a) CNC turned component

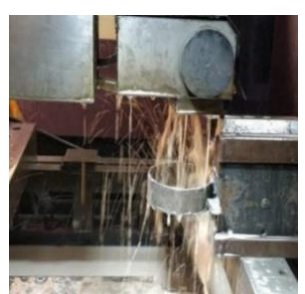

(b) Groove cutting by Wire EDM

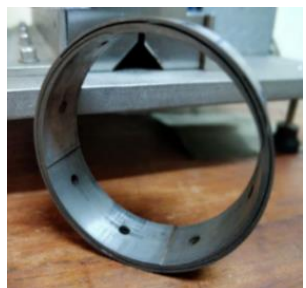

(c) Finished ring after drilling holes by EDM

Figure 3: Photographs showing Sequence of operations performed during the fabrication of ISSFD rings
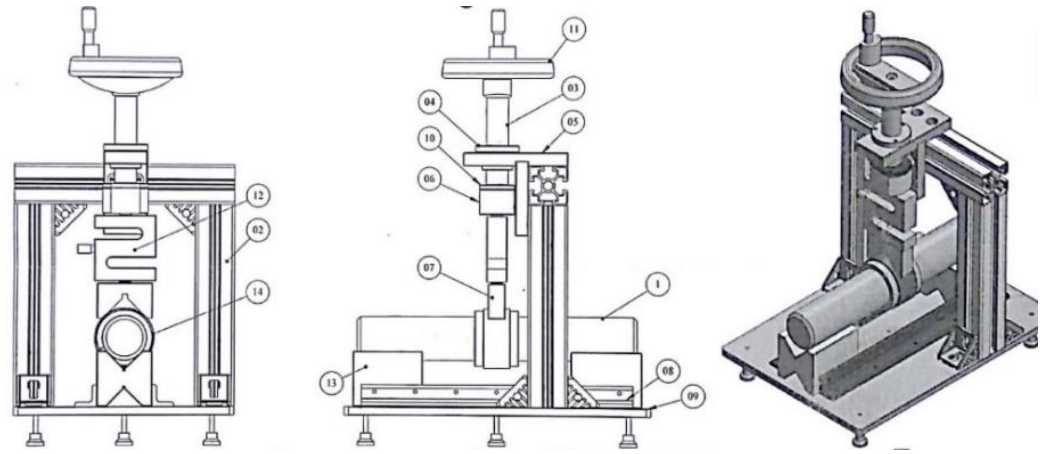

Figure 4. Views of static test rig

1- Mandrel, 2 - Gantry, 3 - Screw rod, 4 - Screw rod nut, 5 - Screw rod plate, 6 - Bearing housing, 7 - Load cell pin 8 - L-Plate, 9 - Base plate, 10 - Top cover, 11 - U Handle, 12 - Load cell, 13 -V Block, 14 - ISSFD ring 


\subsection{Methodology of Measurement}

- Starting from the beginning of a groove, in steps of $15^{\circ}$, ISSFD ring is marked for the entire groove angle in radial direction along the length of groove using a height gauge and indexing head of milling machine. Figure $5 \mathrm{a}$ shows the graphical representation of load line and marking of angular positions for three grooves ISSFD ring with $180^{\circ}$ groove angle. Figure $5 \mathrm{~b}$ shows the photograph of a typical ISSFD ring with marked angular positions.

- The mandrel along with the ISSFD ring is supported between two V-blocks which are mounted on the base plate and ISSFD ring is placed below the loading unit.

- The screw rod is slowly rotated through hand wheel and thereby load is slowly applied in steps on the ISSFD ring and corresponding deflection of groove/slot is noted down at every marking created at intervals of $15^{\circ}$ on the ring.

- Circumferential variation of Stiffness at different marked positions is calculated by finding the slope of load vs deflection.

- The response of stiffness $v_{s}$ groove angle gives a sense of circumferential variation of stiffness of ISSFD ring.

\section{RESULTS AND DISCUSSIONS}

Experiments, parametric in nature were conducted to evaluate the stiffness offered by the ISSFD rings under static condition. The measurement values of load and deflection for all the angular positions of ISSFD rings at intervals of $15^{\circ}$ are noted for each of the ring and the response of Load Vs Deflection is plotted. To have accurate measurements, repeatability of the readings is ensured. Figure $6 \mathrm{a}$ indicates the typical load deflection pattern for a three grooves ISSFD ring with $180^{\circ}$ groove angle. It is observed that after a certain level of loading, there is no increase in the value of deflection at certain positions of groove and a close observation has revealed that it is due to closing of the groove happening under the applied load. Figure $6 \mathrm{~b}$ shows circumferential variation of stiffness up to $120^{\circ}$ position. One can observe decreasing trend in stiffness from $0^{\circ}$ to $60^{\circ}$ position because of overlapping of grooves that has resulted in lesser stiffness and at $90^{\circ}$ position of the groove, there is slight increase in stiffness as a result of single groove. Almost, a mirror image of $0^{\circ}$ to $45^{\circ}$ circumferential variation of stiffness is seen from $45^{\circ}$ to $90^{\circ}$ and the maximum stiffness values are found at $0^{\circ}$ and $90^{\circ}$ positions of the groove. Circumferential variation of Stiffness at different marked positions is calculated and tabulated. Table 1 provides the relevant values of stiffness. Similar patterns are observed for all the other three grooves rings and similar reasons justify the patterns. Figure $7 \mathrm{a}$ and Figure $7 \mathrm{~b}$ show the relevant results obtained for three grooves rings with different groove angles.

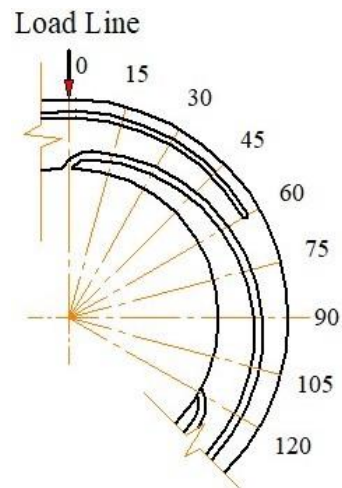

(a)

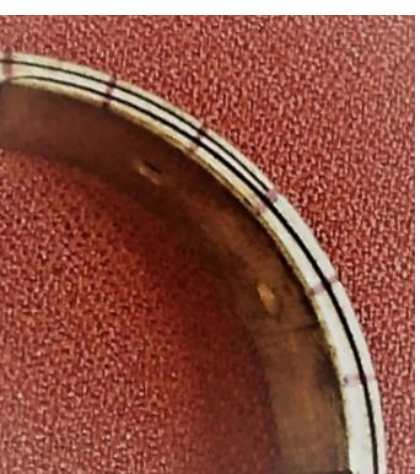

(b)

Figure 5: (a) Graphical representation of load line \& marking of angular positions for 3-grooves ISSFD ring with $180^{\circ}$ groove angle and (b) Photograph of a ring with marked angular positions

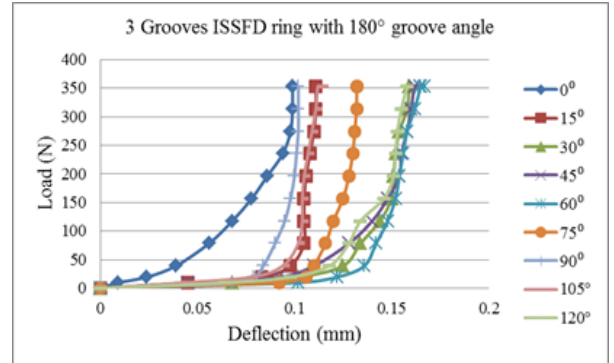

(a) Load $v / s$ Deflection pattern

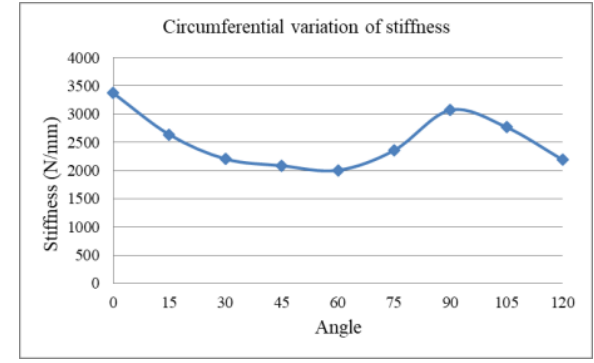

(b) Circumferential variation of Stiffness up to $120^{\circ}$

Figure 6: Details of the results for 3-grooves ISSFD ring with $180^{\circ}$ groove angle 
Table 1: Stiffness values for 3- grooves ISSFD ring with $180^{\circ}$ Groove Angle

\begin{tabular}{|c|c|c|c|c|c|c|c|c|c|}
\hline \multicolumn{2}{|c|}{3 grooves ISSFD ring with $180^{\circ}$ groove angle (Average $\mathrm{K}=2508.86 \mathrm{~N} / \mathrm{mm}$ ) } \\
\hline Loading line position & $0^{\circ}$ & $15^{\circ}$ & $30^{\circ}$ & $45^{\circ}$ & $60^{\circ}$ & $75^{\circ}$ & $90^{\circ}$ & $105^{\circ}$ & $120^{\circ}$ \\
\hline Stiffness $(\mathrm{N} / \mathrm{mm})$ & 3373.61 & 2637.7 & 2204.9 & 2085.7 & 2006.0 & 2356.9 & 3070.2 & 2766.9 & 2188.60 \\
\hline
\end{tabular}

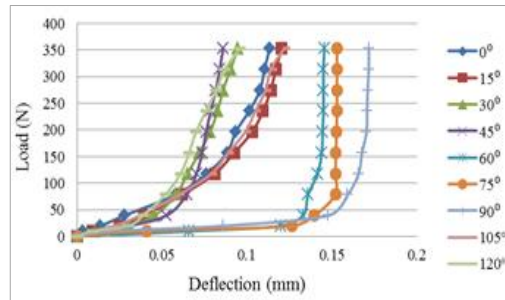

3-grooves ring, $135^{\circ}$ groove angle

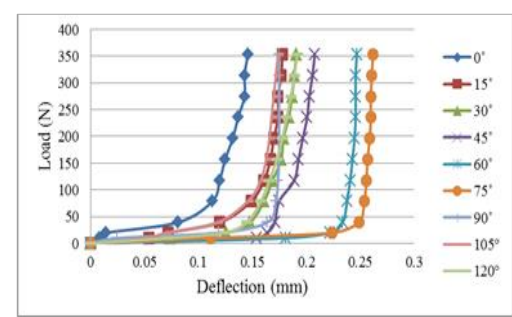

3-grooves ring, $150^{\circ}$ groove angle

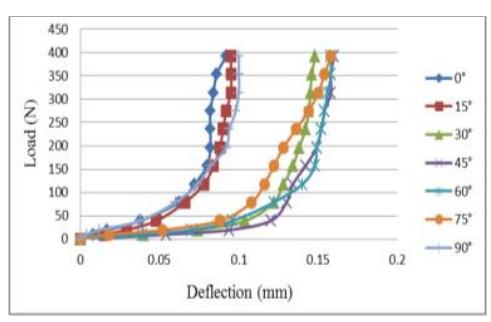

3-grooves ring, $165^{\circ}$ groove angle

Figure 7a: Load v/s Deflection curves for 3-grooves ISSFD rings.

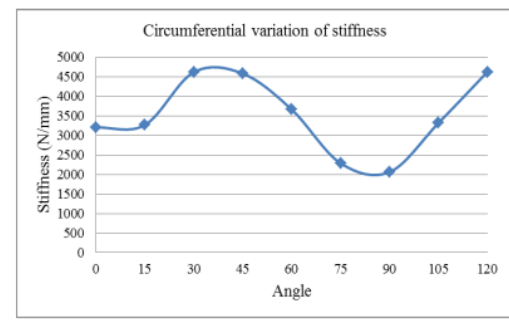

3-grooves ring, $135^{\circ}$ groove angle

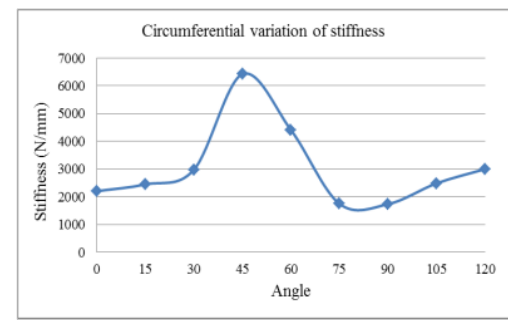

3-grooves ring, $150^{\circ}$ groove angle

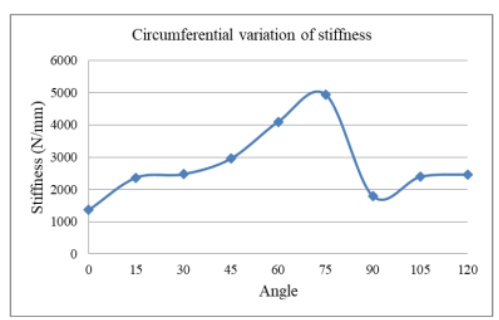

3-grooves ring, $165^{\circ}$ groove angle

Fig 7b: Circumferential variation of Stiffness up to $120^{\circ}$ for 3-grooves ISSFD rings.

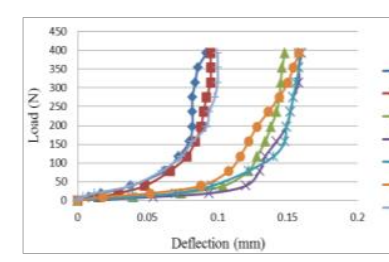

4-grooves, $105^{\circ}$ groove angle

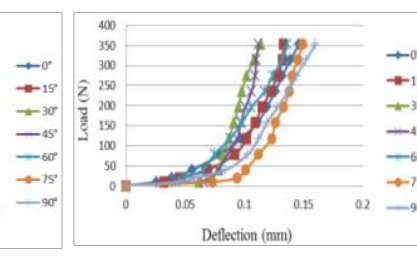

4grooves, $120^{\circ}$ groove angle
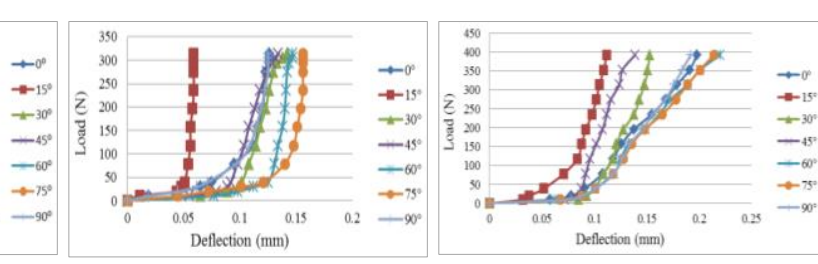

4-grooves, $135^{\circ}$ groove angle 4 -grooves, $150^{\circ}$ groove angle

Fig 8a: Load v/s Deflection curves for 4- grooves ISSFD rings

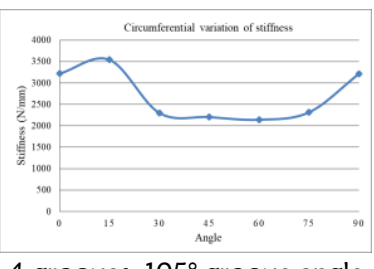

4-grooves, $105^{\circ}$ groove angle
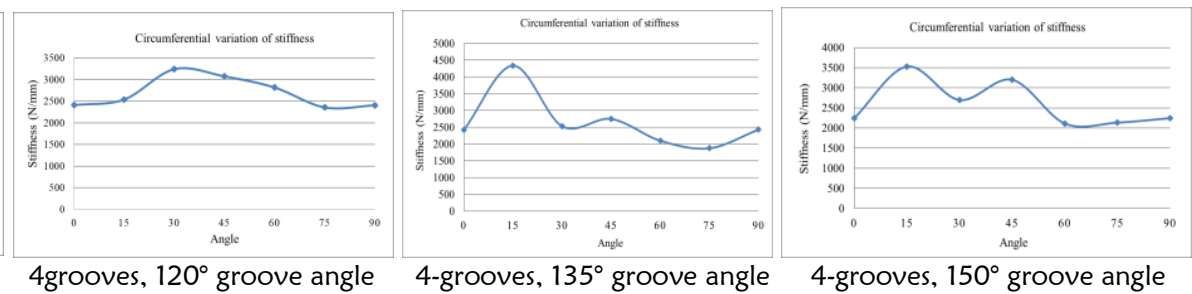

Figure 8b: Circumferential variation of stiffness up to $90^{\circ}$ for 4 - grooves ISSFD rings

Table 2: Average stiffness values of 3 and 4 grooves ISSFD rings

\begin{tabular}{|l|c|c|c|c|c|c|c|c|}
\hline & \multicolumn{4}{|c|}{3 Grooves ISSFD ring } & \multicolumn{3}{c|}{ 4 Grooves ISSFD ring } \\
\hline Groove angle & $135^{\circ}$ & $150^{\circ}$ & $165^{\circ}$ & $180^{\circ}$ & $105^{\circ}$ & $120^{\circ}$ & $135^{\circ}$ & $150^{\circ}$ \\
\hline Stiffness $(\mathrm{N} / \mathrm{mm})$ & 3514.08 & 3045.13 & 2758.97 & 2508.86 & 2704.63 & 2691.04 & 2634.29 & 2592.88 \\
\hline
\end{tabular}




\subsection{Comparative Study of Stiffness on Three and Four Grooves ISSFD Rings}

A comparative study of the average stiffness values of ISSFD rings revealed a typical decreasing trend in stiffness value with the increase in groove angle/groove length/ subtended angle of groove and hence the overlapping angle of grooves for three and four grooves ISSFD rings. Table 2 shows the average stiffness values of ISSFD rings. Figure 9 shows the variation of stiffness for three \& four grooves ISSFD rings for different groove angles. By increasing the groove angle/groove length/subtended angle of groove and hence the overlapping angle of grooves of ISSFD ring, stiffness value is seen to be decreasing. This study has revealed; stiffness of an ISSFD ring is inversely proportional to groove angle/groove length/subtended angle of groove and hence the overlapping angle of grooves. Figure 10a and Figure 10b show graphical representation of circumferential variation of stiffness for three and four grooves ISSFD rings. It is observed that, except for the four grooves ISSFD ring with $120^{\circ}$ groove angle to some extent, all the other rings didn't exhibit axisymmetric pattern of circumferential variation of stiffness. It is also observed that when the overlapping angle of grooves for 3 grooves ring is around $50 \%$ and that for 4 grooves ring is around $66 \%$, the circumferential variation of stiffness is tending to be symmetrical. Therefore increasing the overlapping angle of grooves would increase the axisymmetric pattern of circumferential variation of stiffness. At the same time it is also observed that increasing the overlapping angle would decrease the overall average stiffness value of the ISSFD ring.

\subsection{Development of Six grooves ISSFD ring with $130^{\circ}$ groove angle}

After observing the circumferential variation of stiffness trend on three and four grooves ISSFD rings, a 6 grooves ISSFD ring is developed with a maximum possible $116 \%$ overlap angle of grooves and fabricated. Figure 11a shows the typical drawing \& the photograph, Figure 11b shows Load $\mathrm{v} / \mathrm{s}$ Deflection curves and Figure 11c shows circumferential variation of stiffness up to $60^{\circ}$ for ISSFD ring having six grooves with $130^{\circ}$ groove angle. For all the angular positions, the deflection is seen to be uniform and the Load $\mathrm{v} / \mathrm{s}$ deflection curves are smooth. Figure $11 \mathrm{c}$ shows a plot of circumferential variation of stiffness that is seen to be having symmetric pattern with the profile of the groove. Higher stiffness values are observed at angular positions of $15^{\circ} \& 45^{\circ}$.

One can clearly observe that this ring exhibited axisymmetric pattern of circumferential variation of stiffness. Therefore from static stiffness perspective, this ring is selected as an ideal profile of ISSFD ring and would exhibit best damping performance in an intershaft bearing plane. The average stiffness value of six grooves ISSFD ring is found to be $1.6 \mathrm{MN} / \mathrm{m}$. Table 3 shows the relevant results.
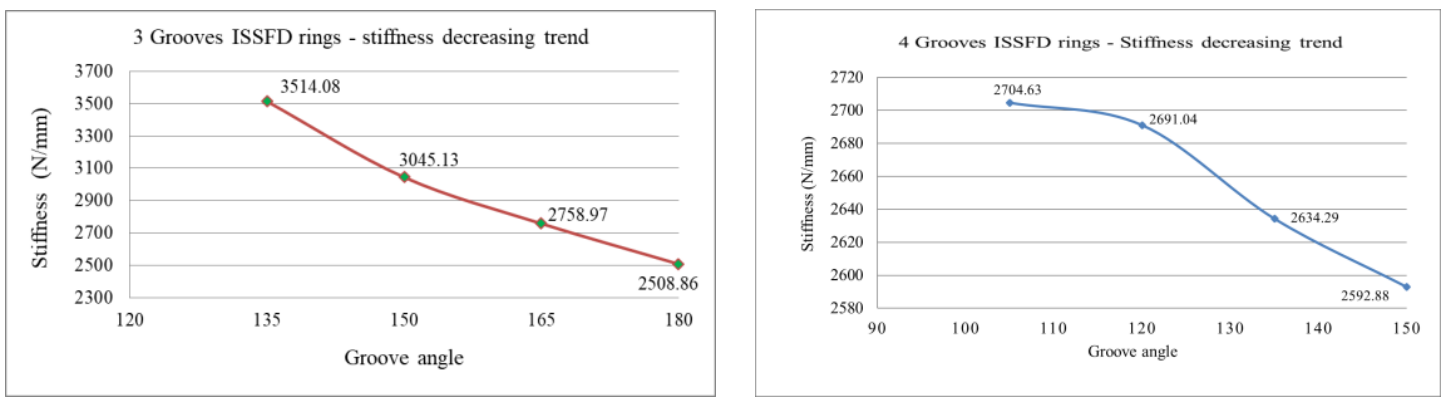

Figure 9: Stiffness variation with groove angle/groove length \& overlap angle of grooves
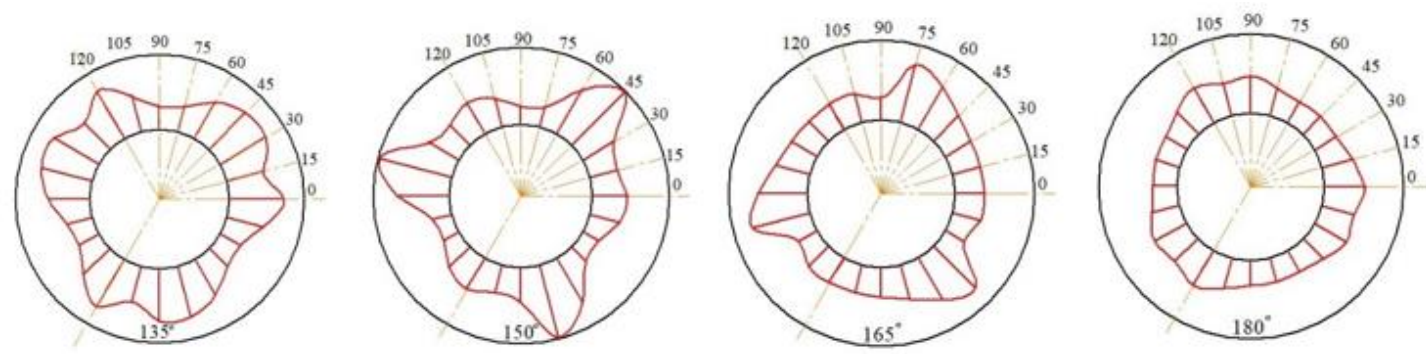

Figure 10a: Graphical representation of circumferential variation of stiffness for 3 grooves ISSFD rings 

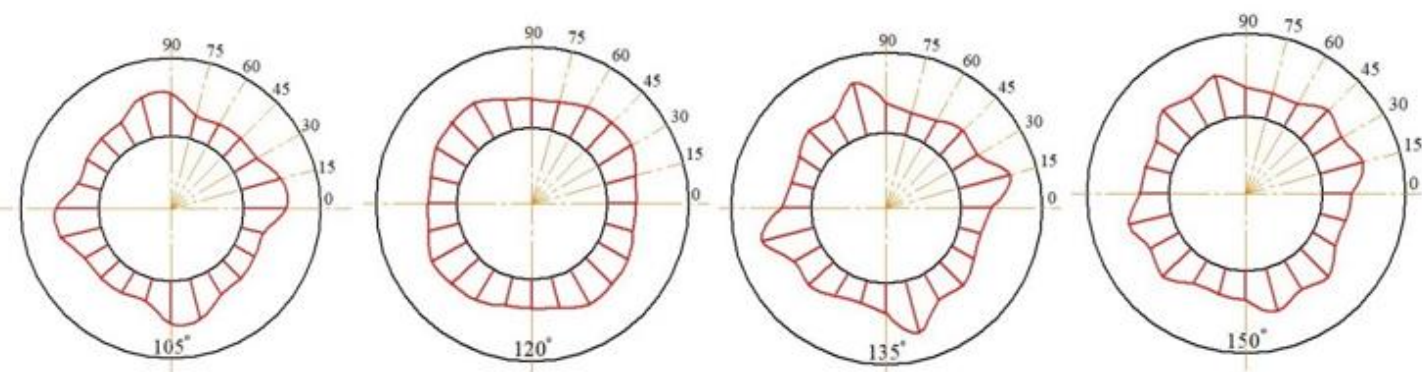

Figure 10b: Graphical representation of circumferential variation of stiffness for 4 grooves ISSFD rings
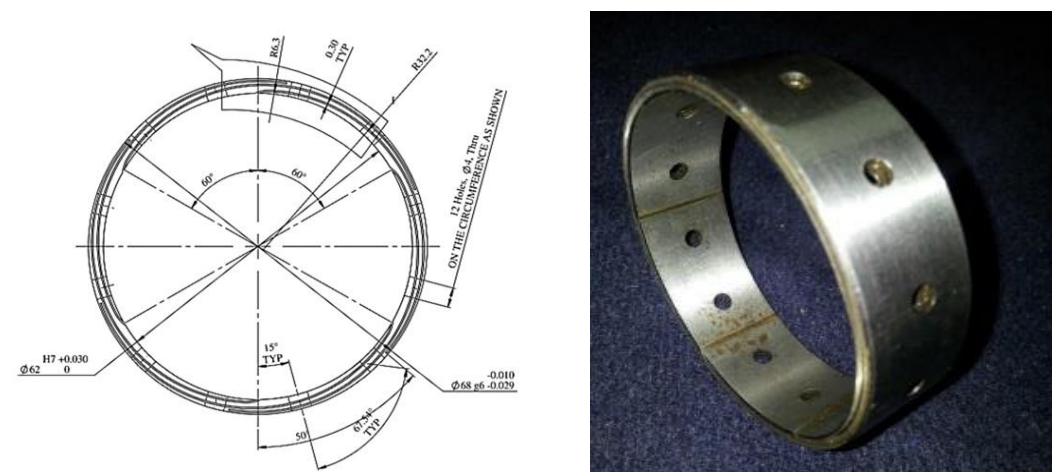

(a) Drawing \& Photograph of 6 grooves ISSFD Ring with $130^{\circ}$ groove angle.

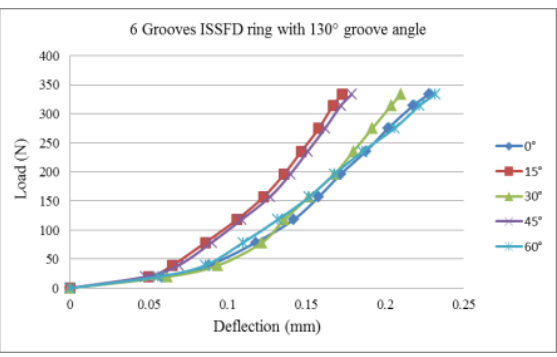

(b) Load $v / s$ Deflection pattern

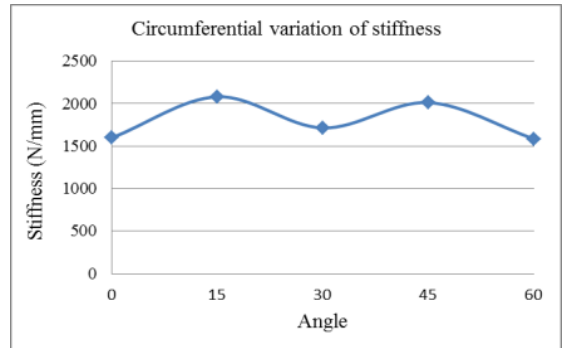

(c) Circumferential variation of Stiffness up to $60^{\circ}$

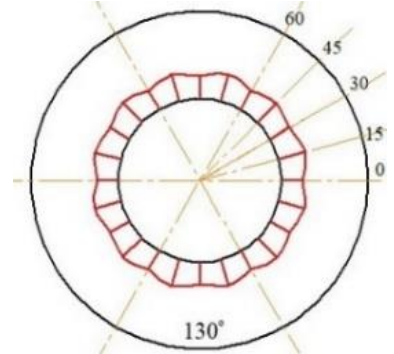

(d) Graphical representation

Figure 11: Details of the results for 6- grooves ISSFD ring with $130^{\circ}$ groove angle

Table 3: Stiffness values for 6 grooves ISSFD ring with $130^{\circ}$ Groove Angle

\begin{tabular}{|c|c|c|c|c|c|}
\hline \multicolumn{6}{|c|}{6 grooves ISSFD ring with $130^{\circ}$ groove angle (Average $\mathrm{K}=1596.49 \mathrm{~N} / \mathrm{mm}$ ) } \\
\hline Loading line position & $0^{\circ}$ & $15^{\circ}$ & $30^{\circ}$ & $45^{\circ}$ & $60^{\circ}$ \\
\hline Stiffness $(\mathrm{N} / \mathrm{mm})$ & 1396.06 & 1879.20 & 1512.86 & 1811.06 & 1383.26 \\
\hline
\end{tabular}

\section{CONCLUSIONS}

1. Two sets of newly conceptualized three and four grooves ISSFD rings with four rings in each set have been fabricated by varying the groove angle/groove length/subtended angle and hence the overlapping angle of grooves as parameters. The rings have been tested on a dedicated static stiffness evaluation test rig and circumferential variations of stiffness of the rings have been studied.

2. The results revealed a typical trend of decreasing average stiffness values of ISSFD rings with the increase in groove angle/groove length/subtended angle and hence the overlapping angle of grooves.

3. None of the three and four grooves ISSFD ring exhibited axisymmetric circumferential variation of stiffness. 
4. A third variety of ISSFD ring having six overlapping grooves with $130^{\circ}$ groove angle is fabricated and circumferential variation of stiffness is evaluated and it exhibited axisymmetric pattern of circumferential variation of stiffness.

5. As an outcome of static stiffness parametric studies, the profile of six grooves ISSFD ring qualifies as an ideal ISSFD ring profile. However the choice could be validated by conducting parametric dynamic tests so that the ring with an ideal profile would exhibit the best possible damping performance in an intershaft bearing plane.

\section{ACKNOWLEDGEMENT}

This research was funded by B.M.S. College of Engineering, Bull Temple road, Bangalore-560 019. The authors are grateful to B.M.S. College of Engineering Management and R\&D Centre of B.M.S. College of Engineering for providing all the facilities required for this research work.

\section{REFERENCES}

1. Dr. Luis San Andres, Notes 13-Squeeze Film Dampers: Operation, Models \& Issues, 2010.

2. Gupta, K., and Samir Chatterjee, (2011). Theoretical Analysis of Improved Designs of Intershaft Squeeze Film Damper for Aero Engine applications. Proceedings of the National Symposium on Rotor Dynamics, NSRD-2011, 19-21, 179-190.

3. Zeidan, F., (1995). Application of Squeeze Film Dampers. Turbo machinery International, Vol.11, 50-53.

4. Zeidan, F., L. San Andrés, and J. Vance, (1996). Design and Application of Squeeze Film Dampers in Rotating Machinery. Proceedings of the 25th Turbo machinery Symposium, Turbo Machinery Laboratory, Texas A\&M University, 169-188.

5. El-Shefai and R.V. Eranki, (1994). Dynamic Analysis of Squeeze Film Damper Supported Rotors Using Equivalent Linearization. ASME Journal for Gas Turbines and power, 1994/7/1, Vol.116, 682-682.

6. El-Shafei, (1991). Stability Analysis of Intershaft Squeeze Film Dampers. Journal of Sound and vibration, 148(3), 395-408.

7. El-Shafei, (1998). A new design of Intershaft Squeeze Film Dampers. Proceedings of the Vibration Institute, 88, 15-23.

8. El-Shafei, (1977). Stable Intershaft Squeeze Film Damper. United States Patent Number - 4,781,077.

9. E. J. Gunter, L.E.Barrett and P.E.Allaire, (1977). Design of Nonlinear Squeeze-Film Dampers for Aircraft Engines. Journal of Lubrication Technology, Vol. 99, Issue 1, 57-64.

10. M.Jayaraman and V.Arun Kumar, (2007). Compact Flexible Support for Rotor Bearing Systems. Project Document from National Aerospace Laboratory.

11. H.M.Shivaprasad and Dr.G.Giridhara, (2018). Preliminary studies of newly conceptualized Intershaft Squeeze Film Damper (ISSFD) Rings. International Journal of Applied Engineering Research, ISSN 0973-4562 Vol. 13(7), 3045310

12. Hibner, D.H., Kirk, R.H. and Buono, D.F., (1977). Analytical and Experimental Investigation of Intershaft Squeeze Film Dampers, Part 1-Demonstation of Instability. Journal of Engineering for Power, Trans. ASME, Vol. 99, Issue 1, 47-52.

13. Hibner, D.H., Bansal, P.N. and Buono, D.F., (1978). Analytical and Experimental Investigation of Intershaft Squeeze Film Dampers, Part 2-Control of Instability. Journal of Mechanical Design, Trans. ASME, Vol. 100(3), 558-562.

14. Alderson, R.G., (1986). Instability of an Intershaft Squeeze Film Damper in a Two-Spool Rotor Dynamics Simulator, Rotor dynamic instability problems in High Performance Turbo machinery. National Air and Space Administration Conference Publications 2443, 315-323.

15. Qihan Li, Litang Yan and J.F. Hamilton, (1986). Investigation of the Steady-State Response of a Dual-Rotor System with Inter-Shaft Squeeze Film Damper. Journal of Engineering for Gas Turbine and Power, Trans. ASME, Volume 108(4), 605-612.

16. Qihan Li, and J.F. Hamilton, (1986). Investigation of the Transient Response of a Dual- Rotor System with Intershaft Squeeze Film Damper. Journal of Engineering for Gas Turbine and Power, Trans. ASME, Volume 108(4), 613-618. 